\title{
WORLDWIDE ASSOCIATIONS BETWEEN AIR QUALITY AND HEALTH END-POINTS: ARE THEY MEANINGFUL?
}

\section{PETER WALLNER, HANS-PETER HUTTER, and HANNS MOSHAMMER}

\author{
Medical University Vienna, Vienna, Austria
}

Institute of Environmental Health

\begin{abstract}
Objectives: The World Health Organization (WHO) provides data on national indices of health, environment and economy. When we were asked, why air pollution is negatively correlated with cancer mortality, our first response (presumably the mortality data are not age-adjusted) was not sufficient to explain the paradox. Material and Methods: A table including all-cause, cancer and childhood mortality, life expectancy, gross national product per person, smoking prevalence, physician density and particulate matter $\left(\mathrm{PM}_{10}\right)$ per country $(\mathrm{N}=193)$ was developed. For explorative purposes weighted crosssectional multiple linear regressions models were built. Results: Air pollution is positively correlated with infant and overall mortality and negatively with life expectancy. This might not only depict a true causal effect of $\mathrm{PM}_{10}$ because air quality is also an indicator of a country's prosperity and general state of environment. Cancer mortality is negatively correlated with $\mathrm{PM}_{10}$. However, this association turns positive when economic or health system indicators are controlled. Conclusions: The World Health Organization's world-wide data sets demonstrate the large disparity of our world. A careful and professional approach is needed as interpretation is difficult, especially for lay persons. Therefore, with publicly available data WHO should also provide interpretation and guidance.
\end{abstract}

Key words:

Air quality, Environmental health, Cancer, WHO, Ecological study, Teaching

\section{INTRODUCTION}

In the population of laymen "cancer" is often seen as a hallmark health effect of toxic environmental exposure. Although, indeed, some environmental exposures add to the risk of some kinds of cancer, the relative risks involved are usually much smaller than it is perceived by a concerned citizen [1-3].

Publically available data provided by a trusted organisation, such as the World Health Organization (WHO), would be well suited to educate the general public and to foster a more accurate perception of environmental risks and health effects related to them.

During our lecture on environmental public health at the Medical University, the students raised a series of questions concerning interpretation of specific WHO global data sets, namely the WHO Global Health Observatory Data Repository [4], and the WHO, Department of Measurement and Health Information, Mortality and Burden of Disease Estimates for WHO Member States in 2004 [5]. From the former the students selected

Received: March 11, 2014. Accepted: May 2, 2014.

Corresponding author: H. Moshammer, Institute of Environmental Health, Center for Public Health, Medical University of Vienna, Kinderspitalgasse 15, A-1090 Vienna, Austria (e-mail: hanns.moshammer@meduniwien.ac.at). 


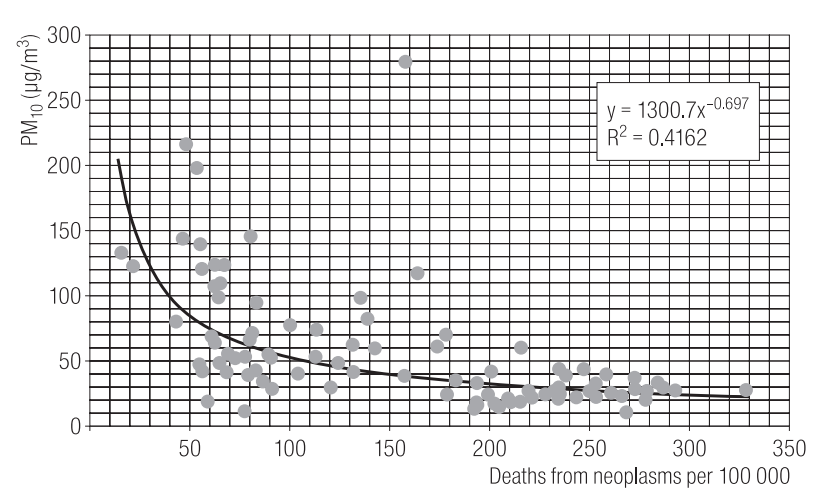

$\mathrm{PM}_{10}$ - particulate matter with an aerodynamic diameter less than $10 \mu \mathrm{m}$.

Fig. 1. Scatter plot as prepared by the students displaying country-wise annual $\mathrm{PM}_{10}$ concentration and annual deaths from neoplasms per 100000 (raw data)

"Environmental Health / Outdoor Air Pollution / Exposure / Country Level" obtaining a table with country estimates of the (population weighted) exposure to particulate matter smaller than $10 \mu \mathrm{m}\left(\mathrm{PM}_{10}\right)$. Particulate matter data were available from 193 countries and stemmed from the years 2003-2010. Coverage of the monitoring system is likely to differ between the countries, therefore, also accuracy of the exposure classification is deemed to differ between the countries. From the latter data set the students selected "Death rates." This table reports "Estimated deaths per 100000 population by cause, and Member State, 2004" as raw data (not age-adjusted, although age-adjusted rates are available in the same Excel-file in another table). The students also chose "Malignant neoplasms" as an endpoint of primary interest.

They expected to find a clear positive association between air pollution and cancer mortality [6]. Thus, we have reproduced the scatter-plot prepared by the students (Figure 1). Interestingly, it depicted $\mathrm{PM}_{10}$ as a dependent and mortality by cancer as an independent variable and it found a clearly negative, although non-linear association between both of the variables.

First, we told them that age-adjusted data would be more reliable but upon analysing age-adjusted data we noticed that cancer mortality and $\mathrm{PM}_{10}$ were still negatively, though weakly, correlated with each other. Therefore, we decided to investigate the issue further.

\section{MATERIAL AND METHODS}

Country-specific data were obtained from the various WHO data-sets: population number (in 100 000), allcause mortality (per 100 000, age-adjusted only), cancer (per 100 000, age-adjusted and raw data), childhood mortality (per 1000 live births), life expectancy, gross national product (GNP) per person, smoking prevalence, physician density (per 10000 ), and $\mathrm{PM}_{10}$. In order to visualise the association between cancer deaths (age adjusted) and $\mathrm{PM}_{10}$ the scatter-plot (Figure 1) was improved in several ways (Figure 2), i.e., dependent and independent variables were exchanged, raw cancer death data were replaced by age-adjusted data, and population size was expressed by the size of each dot. To achieve the latter, the data were manually recoded to fit the format of the free Gapminder program [7].

For explorative purposes weighted cross-sectional multiple linear regressions models were built. First, we generated a model resembling the approach of our students: a linear regression model with cancer mortality (raw data) as a dependent and $\mathrm{PM}_{10}$ as an independent variable. In the second step we improved the model through weighting by population number. We applied the "aweights" option for analytical weights in Stata. Analytic weights are weights that are inversely proportional to the variance of an observation. This option reflects the fact that countries with a smaller population number provide a less precise estimate and are less influential in the case of world-wide health status. Next, we replaced raw cancer mortality data by age-adjusted data. Then, in several steps, we added other potential confounding variables to the model, each separately: gross national product per person, smoking prevalence and physician density. As the next step we also investigated, in a similar way, the association between 


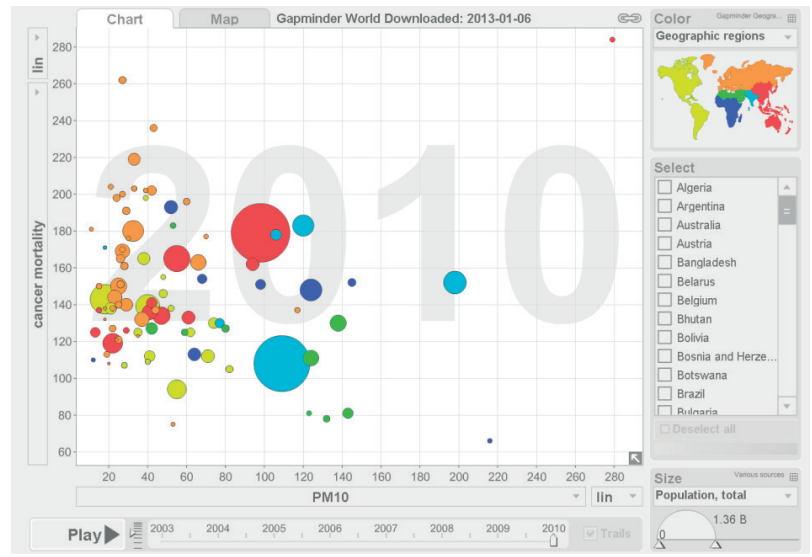

$\mathrm{PM}_{10}$ - as in Figure 1.

Fig. 2. Extended scatter-plot produced with the free program Gapminder country-wise displaying annual deaths from neoplasms per 100000 (age-adjusted data) and annual $\mathrm{PM}_{10}$ concentration

$\mathrm{PM}_{10}$ and other health parameters (life expectancy, infant mortality, all-cause mortality).

\section{RESULTS AND DISCUSSION}

The world-wide ranges of the investigated variables are shown in Table 1. $\mathrm{PM}_{10}$, gross national product, smoking prevalence, and physician density were all taken into account as factors that possibly influence population health indicators. $\mathrm{PM}_{10}$ was significantly negatively correlated with all the other variables ( $\mathrm{R}$ between -0.34 and -0.57 ). Age-adjusted mortality due to cancer and due to all causes, infant mortality and life expectancy were considered as indicators of population health. Cancer mortality was not significantly associated with the other indicators, while all the other indicators were correlated with one another: as expected, higher life expectancy went along with lower overall and infant mortality (data not shown).

The findings regarding cancer deaths are presented in Table 2. Raw data on cancer deaths are negatively correlated with $\mathrm{PM}_{10}$. Population weighted analysis did not lead to a substantially different outcome. Age-adjusted cancer death data are less strongly, but still negatively correlated with $\mathrm{PM}_{10}$. Upon inclusion of smoking prevalence or physician density, the regression coefficient for $\mathrm{PM}_{10}$ turned positive and model fit improved. Not surprisingly the percentage of smokers had a strong impact on cancer mortality in this simplified ecological study. We assume that in the case of countries with a low physician density (as an indicator of poor health services) cancer cases might be underdiagnosed or underreported. Even in the age-adjusted analysis competing causes of death might still be an issue. Life expectancy, infant mortality and all-cause mortality generally showed more "unhealthy" outcomes with higher

Table 1. World-wide range of national data relevant for health

\begin{tabular}{lrrrr}
\hline \multicolumn{1}{c}{ Variable } & $\begin{array}{c}\text { Country } \\
{[\mathrm{n}]}\end{array}$ & $\mathrm{M}$ & Min. & Max \\
\hline Gross national product (USD/person) & 167 & 12286 & 320 & 61240 \\
$\mathrm{PM}_{10}\left(\mu \mathrm{g} / \mathrm{m}^{3}\right)$ & 91 & 57 & 11 & 279 \\
Smokers (\%) & 146 & 17 & 2 & 55 \\
Physician density (per 10 000) & 68 & 24 & 0.85 & 61.67 \\
Cancer mortality (age-adjusted, per 100 000) & 193 & 144 & 59 & 284 \\
Life expectancy (years) & 193 & 69 & 47 & 83 \\
Infant mortality (per 1000 live births) & 193 & 33 & 2 & 133 \\
All-cause mortality (age-adjusted, per 100 000) & 193 & 940 & 220 & 3147 \\
\hline
\end{tabular}

$\mathrm{PM}_{10}$ - as in Figure 1.

M - mean; Min. - minimum value; Max - maximum value. 
Table 2. Apparent effect of $\mathrm{PM}_{10}$ on cancer mortality and indicators of model fit

\begin{tabular}{lccc}
\hline \multicolumn{1}{c}{ Model } & Coefficient & $\mathrm{p}$ & Adjusted R \\
\hline Raw data & -0.95 & $<0.001$ & 0.29 \\
Raw data, population weighted & -1.07 & $<0.001$ & 0.45 \\
Age-adjusted, unweighted & -0.03 & 0.695 & 0.00 \\
Age-adjusted, weighted & -0.06 & 0.469 & 0.01 \\
Age-adjusted, weighted & -0.05 & 0.700 & 0.00 \\
$\ldots$ + gross national product & -0.00 & 0.876 & \\
Age-adjusted, weighted & 0.18 & 0.306 & 0.08 \\
$\ldots$ + physician density & 1.68 & 0.032 & \\
Age-adjusted, weighted & 0.23 & 0.001 & 0.55 \\
$\ldots$ + percentage of smokers & 2.87 & $<0.001$ & \\
\hline
\end{tabular}

$\mathrm{PM}_{10}$ - as in Figure 1.

$\mathrm{PM}_{10}$, even before confounder adjustment (Table 3). As expected, better economic status (as captured by GNP) and better health-care (physician density) were related to a better health status. Surprisingly, the percentage of smokers was also positively related to the general health indicators. This paradox association was attenuated although not reversed after controlling for the countries' economic status (GNP). The percentage of smokers is, indeed, higher in richer countries $(\mathrm{R}=0.34, \mathrm{p}=0.001)$. Residual confounding by economic conditions as well as latency issues with the temporal course of the tobacco epidemic [8] could likely explain most of this findings.

This is an ecological study and therefore, it does not allow causal interpretation. Disregarding that rule might lead to ecological fallacy as exemplified by the long-lasting debate about apparently protective effects of radon against lung cancer $[9,10]$.

Nevertheless, data concerning ecological studies are often easy to obtain and the findings are often very intuitive. Therefore, they can be highly valuable for educational purposes like lectures and also for risk communication [11]. In case of a well-established causal association and in the absence of strong confounders (as in the case of smoking and lung cancer) this kind of studies also informs about the "true" magnitude of the effects in the "real world."
However, when lecturing on air pollution and cancer one should also mention that there is a large body of experimental and human biomonitoring studies, which demonstrate the association of air pollution with mutagenicity, genotoxicity and epigenetic modification [6].

The global variation in health - which is highly unfair and should be tackled vigorously - provides an opportunity to investigate the range of inequality between societies and the correlation between indicators of health and environment. In this context, air pollution serves rather as an indicator of general environmental quality and living standards in a country: a country that lacks resources, power or dedication to protect the air the citizens breath will also most likely fail to provide for clean drinking water and other fundamental necessities. Data collected by WHO are of different quality. Differential misclassification of air pollution is possible especially because the countries with poor air quality will also often lack a sophisticated monitoring system, as monitoring stations require high investments and maintenance costs. Similarly, annual mean levels of $\mathrm{PM}_{10}$ are not equally representative of population exposure in each country. The problem of data quality is also exemplified by the fact that air pollution data are reported from different years, which might introduce bias in the case of systematic temporal trends in air quality. 
Table 3. Apparent effect of $\mathrm{PM}_{10}$ and other factors of possible relevance on health indicators other than cancer mortality

\begin{tabular}{|c|c|c|}
\hline Model & Coefficient & $\mathrm{p}$-value \\
\hline \multicolumn{3}{|l|}{ Life expectancy } \\
\hline $\mathrm{PM}_{10}$ & -0.10 & $<0.001$ \\
\hline gross national product & 0.0004 & $<0.001$ \\
\hline physician density & 0.45 & $<0.001$ \\
\hline$\%$ of smokers & 0.52 & $<0.001$ \\
\hline \multicolumn{3}{|l|}{ All-cause mortality } \\
\hline $\mathrm{PM}_{10}$ & 3.57 & $<0.001$ \\
\hline gross national product & -0.02 & $<0.001$ \\
\hline physician density & -16.70 & $<0.001$ \\
\hline$\%$ of smokers & -24.30 & $<0.001$ \\
\hline \multicolumn{3}{|l|}{ Infant mortality } \\
\hline $\mathrm{PM}_{10}$ & 0.38 & $<0.001$ \\
\hline gross national product & -0.001 & $<0.001$ \\
\hline physician density & -1.67 & $<0.001$ \\
\hline$\%$ of smokers & -2.04 & $<0.001$ \\
\hline
\end{tabular}

$\mathrm{PM}_{10}-$ as in Figure 1.

Satellite data might help to overcome these shortcomings in the future [12]. However, also the quality of health data constitutes a well-recognised problem [13].

Gapminder is a free program that is well suited for presentation of complex data. When used with own data its handling is somehow complicated because of its own special data format. However, when these initial problems are overcome it can be effectively used for educational purposes.

\section{CONCLUSIONS}

The global data sets provided by WHO are informative and constitute a valuable tool for public health education and risk communication. Nevertheless, there is a need to educate lay persons (also students) how to read the data correctly. Otherwise, one faces the risk of misinterpretation. The data should come with a short introduction including the concept of age-adjustment, possible confounders, and the relative importance of various environmental causes for selected diseases or groups of diseases.

\section{ACKNOWLEDGMENTS}

The study was performed upon a request of students during our environmental public health lecture. We thank our students for their vital interest in these issues.

\section{REFERENCES}

1. Slovic P. The perception of risk. London: Earthscan; 2000.

2. Wallner P, Haidinger G. [Environment and cancer as seen by the population of Austria]. Bundesgesundheitsbl Gesundheitsforsch Gesundheitsschutz. 1999;42:327-31. German.

3. Luria P, Perkins C, Lyons M. Health risk perception and environmental problems. Findings from ten case studies in the North West of England. Summary report. Liverpool: 
Centre for Public Health, Research Directorate, Faculty of Health and Applied Social Sciences, John Moores University Kingsway House, Hatton Garden; 2009.

4. World Health Organization. Global health observatory data repository [cited 2014 Jan 13]. Available from: http://apps. who.int/gho/data/node.main.

5. World Health Organization. Mortality and burden of disease estimates for WHO member states in 2004. WHO, Department of Measurement and Health Information [cited 2014 Jan 13]. Available from: http://www.who.int/ healthinfo/global_burden_disease/gbddeathdalycountryestimates2004.xls.

6. Straif K, Cohen A, Samet J, editors. IARC Scientific Publication No. 161. Air pollution and cancer. Lyon: International Agency for Research on Cancer; 2013.

7. Gapminder [Internet]. Lyon: International Agency for Research on Cancer; 2013 [cited 2014 Jan 13]. Available from: http://www.gapminder.org.

8. Thun M, Peto R, Boreham J, Lopez AD. The tobacco epidemic today. Stages of the cigarette epidemic on entering its second century. Tob Control. 2012;21:96-101.
9. Cohen BL. Test of the linear-no threshold theory of radiation carcinogenesis for inhaled radon decay products. Health Phys. 1995;68:157-74, http://dx.doi.org/10.1097/ 00004032-199502000-00002.

10. Lubin JH. On the discrepancy between epidemiologic studies in individuals of lung cancer and residential radon and Cohen's ecologic regression. Health Phys. 1998;75:4-10.

11. Hunka A, Palmqvist A, Thorbek P, Forbes V. Risk communication discourse among ecological risk assessment professionals and its implications for communication with nonexperts. Integr Environ Assess Manag. 2013;9:616-22, http:// dx.doi.org/10.1002/ieam.1426.

12. Hyder A, Lee HJ, Ebisu K, Koutrakis P, Belanger K, Bell ML. PM 2.5 exposure and birth outcomes: Use of satellite- and monitor-based data. Epidemiology. 2014;25: 58-67, http://dx.doi.org/10.1097/EDE.0000000000000027.

13. World Health Organization, Regional Office for the Western Pacific. Improving data quality: A guide for developing countries. Manila: WHO Regional Office; 2003 [cited 2014 Jan 21], http:/www.wpro.who.int/publications/docs/Improving_Data_Quality.pdf.

This work is available in Open Access model and licensed under a Creative Commons Attribution-NonCommercial 3.0 Poland License - http://creativecommons.org/ licenses/by-nc/3.0/pl/deed.en. 